\title{
Some Aspects of Barreling in Sintered Plain Carbon Steel Powder Metallurgy Preforms During Cold Upsetting
}

\author{
Sumesh Narayan*, Ananthanarayanan Rajeshkannan \\ Mechanical Engineering, School of Engineering and Physics, Faculty of Science, Technology \& Environment, \\ University of the South Pacific, Laucala Campus, PO Box 1168, Suva, Fiji
}

Received: August 30, 2011; Revised: January 24, 2012

\begin{abstract}
The present research establishes a relationship of bulged diameter with densification and hydrostatic stress in forming of sintered iron $(\mathrm{Fe}$ ) powder metallurgy preforms cold upset under two different frictional conditions, namely, nil/no and graphite lubricant condition. Sintered plain carbon steel cylindrical preforms with carbon $(C)$ contents of $0,0.35,0.75$ and $1.1 \%$ with constant initial theoretical density of $84 \%$ and aspect ratio of 0.4 and 0.6 were prepared using a suitable die-set assembly on a $1 \mathrm{MN}$ capacity hydraulic press and sintered for 90 minutes at $1200^{\circ} \mathrm{C}$. Each sintered preform was cold upset under two different frictional constraints. It is seen that the degree of bulging reduces with reducing frictional constraints at the die contact surface. Further, it is found that the bulging ratio changed as a function of relative density and hydrostatic stress, respectively, according to the power law equations.
\end{abstract}

Keywords: barreling, densification, aspect ratio, fracture

\section{Introduction}

Powder metallurgy (P/M) preforms are prepared in various steps that involve powder mixing, compacting and sintering known as primary deformation processes. A known limitation of this route is the residual porosity left in preforms after the sintering process. Plastic deformation is a main way to improve the performance of sintered ferrous material and obtain the final product. In general, the preform produced by the conventional process will undergo large degree of plastic deformation with enhanced level of densification ${ }^{1,2}$. Even though plastic deformation of powder preforms is similar to that of conventional fully dense materials, there are additional complications because of substantial amount of void fractions. The prediction of failure in powder preform forging is important in die design and selection of preform geometry, since material properties may affect the final shape of a deformed workpiece and may cause defects such as cracks or folds ${ }^{3,4}$.

Since the primary cause of fracture in upsetting is the circumferential tensile stresses, it is therefore essential to investigate fracture during cold upsetting of sintered powder materials $^{5-7}$. The presence of friction at the die contact surfaces directly affects the plastic deformation and is a major concern in metal forming operations. Narayanasamy and Pandey ${ }^{8}$ showed that the barrel radius can be expressed as a power-law function of the compressive stresses for the case of fully dense material and can be expressed theoretically as a function of height strain. Many studies ${ }^{6-9}$ have been conducted to predict the deformed shape of the porous $\mathrm{P} / \mathrm{M}$ cylindrical preform. A conical wedge of a relatively undeformed material is formed immediately below the deforming specimen while other parts of the

*e-mail: narayan_su@usp.ac.fj cylinder undergoes high strain hardening and bulges out in a form of a barrel (as shown in Figure 1). The induced stress and strain are no longer uniform due to barreling, that depends on the friction condition at the die work piece contact surface ${ }^{8-10}$. It is reported ${ }^{11}$ by studying progression of barreling phenomena and variation of total surface area according to the increase of barreling that the total surface area decreases at low upset ratios for long specimens $(h / d=1)$ and then begins to increase. Thaheer et al. ${ }^{12}$ and Narayanasamy et al. ${ }^{13}$ presented that the barrel radius follows a power law relationship with new geometrical shape factor. Lubrication is important in most metal forming processes particularly in cold metal forming. This is because good lubrication improves the quality of products through the reduction of defects and improvement in the dimensional accuracy and surface finish. Lubrication also influences metal flow in a generally beneficial manner with respect to crack formation ${ }^{14-16}$. It is shown ${ }^{17}$ that both the temperature and the strain rate affect the lubrication performance of the graphite film applied at the die-specimen interfaces.

The important parameters controlling the metal flow during the upset forging are the preform shape, dimensions and density. It is well understood that increasing the density of the $\mathrm{P} / \mathrm{M}$ parts is the best way to increase the performance of these parts. However, the essential governing factor for such design is found to be that the final product must be free from defects such as cracks ${ }^{18-20}$. Thus, the present investigation is aimed to establish the bulging behaviour of powder metallurgy preforms of $\mathrm{Fe}, \mathrm{Fe}-0.35 \% \mathrm{C}$, $\mathrm{Fe}-0.75 \% \mathrm{C}$ and $\mathrm{Fe}-1.1 \% \mathrm{C}$ experimentally (cold upset forging) with the influence of aspect ratio and lubricant conditions, namely, nil/no and graphite lubricant. Further, 
to establish the technical relationship that exists between the characteristics of densification with respect to bulging ratio $\left(\mathrm{D}_{\mathrm{b}} / \mathrm{D}_{\mathrm{o}}\right)$ and actual bulged strain, respectively, and the technical relationship that exists between hydrostatic stress and actual bulged strain.

\section{Experimental Details}

\subsection{Materials and characterization}

Atomized iron powder of less than or equal to $150 \mu \mathrm{m}$ size and graphite powder of 2-3 $\mu \mathrm{m}$ size were used in the present investigation. Analysis indicated that the purity of iron was 99.7 percent and the rest were insoluble impurities. The characteristics (apparent density, flow rate and particle size distribution) of iron powder, Fe- $0.35 \% \mathrm{C}, \mathrm{Fe}-0.75 \% \mathrm{C}$ and $\mathrm{Fe}-1.1 \% \mathrm{C}$ blends are shown in Tables 1 and 2 .

\subsection{Blending, compaction and sintering}

A powder mix corresponding to $\mathrm{Fe}-0 \% \mathrm{C}, \mathrm{Fe}-0.35 \% \mathrm{C}$, $\mathrm{Fe}-0.75 \% \mathrm{C}$ and $\mathrm{Fe}-1.1 \% \mathrm{C}$ was taken in a stainless steel pot with the powder mixed using porcelain balls $(10-15 \mathrm{~mm}$ diameter) with a ratio of $1: 1$ by weight. The pot containing the blended powder was subjected to the blending operation by securely tightening and then fixing it to the pot mill. The mill was operated for 20 hours to obtain a homogenous mix. Green compacts of $28 \mathrm{~mm}$ diameter with $12 \mathrm{~mm}$ length were prepared. The powder blend was compacted on a 1.0 MN hydraulic press using a suitable die, a punch and a bottom

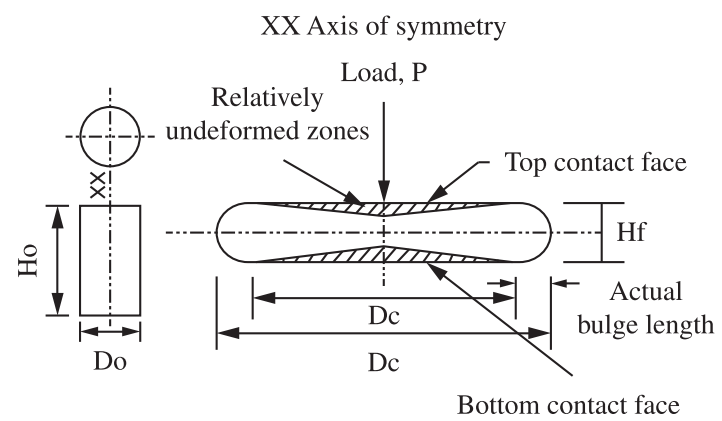

(a) Initial cylinder

(b) Instantaneous barrel

Figure 1. Schematic representation of upset forging test specimen (a) before and (b) after deformation. insert in the pressure range of $430 \pm 10 \mathrm{MPa}$ to obtain an initial theoretical density of $0.84 \pm 0.01$. In order to avoid oxidation during sintering and cooling, the entire surface of the compacts were indigenously formed with ceramic coating. These ceramic coated compacts were heated in the electric muffle furnace at a temperature of $1200 \pm 10{ }^{\circ} \mathrm{C}$. At this temperature, the compacts were sintered for 90 minutes followed by furnace cooling.

\subsection{Cold deformation}

Sintered and furnace cooled preforms were machined to such a dimension so as to provide height-to-diameter ratio of 0.4 and 0.6 , respectively. The initial dimensions of the cylindrical preforms were measured and recorded and used to calculate the initial density. Each specimen was compressively deformed between a flat die-set in the incremental loading step of $0.05 \mathrm{MN}$ using $1 \mathrm{MN}$ capacity hydraulic press under friction conditions, which included dry, unlubricated dies called nil/no lubricant condition and lubrication consisting of graphite paste (i.e. graphite with acetone). The deformation process was stopped once a visible crack appeared at the free surface. Dimensional measurements such as deformed height, deformed diameters (including bulged and contact) were carried out after every step of deformation using digital vernier caliper and the density measurements being carried out using the Archimedes principle. Experimental results were used to calculate the flow stress, true height strain, percentage theoretical density, fracture strains and hydrostatic stress.

\section{Results and Discussion}

Figures 2 and 3 shows the relationship between relative density and bulging ratio of plain carbon steel P/M preforms of aspect ratio of 0.4 and 0.6 , respectively, cold upset under two different frictional conditions, namely, nil/no and graphite lubricant condition. The characteristic nature of the curves is similar. As the bulging ratio increases densification also increases; however, it follows three different mechanisms of densification irrespective of percentage of carbon content, aspect ratio and frictional constraints. It can be noted that the densification is higher during the initial stages (1-1.12 bulging ratio) of deformation with reduced material flow in the lateral direction. During the initial stages of deformation a large number of pores are present, thus bigger pores collapse and close with

Table 1. Characterization of iron powder.

\begin{tabular}{clcccc}
\hline Si. $\mathbf{n}^{\mathbf{0}}$ & \multicolumn{1}{c}{ Property } & Iron & $\begin{array}{c}\text { Fe-0.35\%C } \\
\text { blend }\end{array}$ & $\begin{array}{c}\text { Fe-0.75\%C } \\
\text { blend }\end{array}$ & $\begin{array}{c}\text { Fe-1.1\%C } \\
\text { blend }\end{array}$ \\
\hline 1. & Apparent density $(\mathrm{g} / \mathrm{cc})$ & 3.38 & 3.37 & 3.29 & 3.21 \\
2. & Flow rate, $(\mathrm{s} / 50 \mathrm{~g})$ by hall flow meter & 26.3 & 28.1 & 25.3 & 24.8 \\
3. & Compressibility $(\mathrm{g} / \mathrm{cc})$ at pressure of $430 \pm 10 \mathrm{MPa}$ & 6.46 & 6.26 & 6.41 & 6.35 \\
\hline
\end{tabular}

Table 2. Sieve size analysis of iron powder.

\begin{tabular}{cccccccc}
\hline Sieve size $(\boldsymbol{\mu m})$ & $\mathbf{1 5 0}$ & $\mathbf{+ 1 2 5}$ & $\mathbf{+ 1 0 0}$ & $\mathbf{+ 7 5}$ & $\mathbf{+ 6 3}$ & $\mathbf{+ 4 5}$ & $\mathbf{- 4 5}$ \\
\hline wt. $(\%)$ ret. & 10.60 & 24.54 & 15.46 & 19.90 & 11.10 & 8.40 & 10.00 \\
\hline
\end{tabular}


little enhancement in lateral direction material flow. The second stage (1.12-1.27 bulging ratio) follows steady state response indicating the pore closing rate has decreased with enhancement in lateral deformation and at the final stage very little increase in densification is observed. Furthermore, for any given bulging ratio, densification for pure iron is found to be the lowest followed by $\mathrm{Fe}-1.1 \% \mathrm{C}$, then $\mathrm{Fe}$ $0.75 \% \mathrm{C}$ and highest for $\mathrm{Fe}-0.35 \% \mathrm{C}$. It can be seen (Figure 4 )

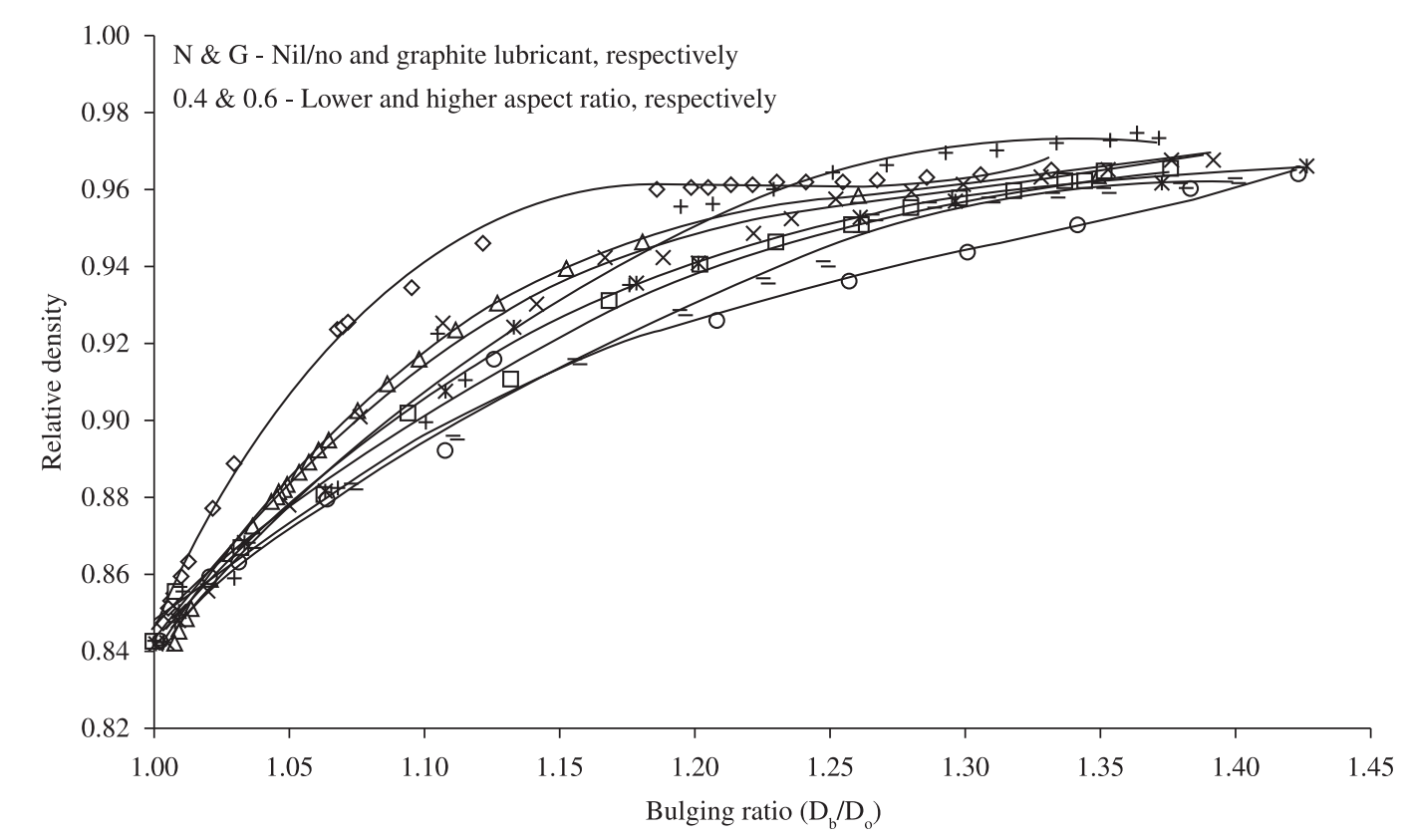

$\diamond \mathrm{Fe}-0.35 \% \mathrm{C},(\mathrm{N}),(0.4) \quad \Delta \mathrm{Fe}-0.35 \% \mathrm{C},(\mathrm{G}),(0.4) \quad \square \mathrm{Fe},(\mathrm{N}),(0.4) \quad \mathrm{OFe},(\mathrm{G}),(0.4) \quad \times \mathrm{Fe}-0.75 \% \mathrm{C},(\mathrm{N}),(0.4)$ $* \mathrm{Fe}-0.75 \% \mathrm{C},(\mathrm{G}),(0.4)+\mathrm{Fe}-1.1 \% \mathrm{C},(\mathrm{N}),(0.4)-\mathrm{Fe}-1.1 \% \mathrm{C},(\mathrm{G}),(0.4)$

Figure 2. Variation of relative density against bulging ratio of plain carbon steel P/M preforms of aspect ratio of 0.4 during cold upsetting.

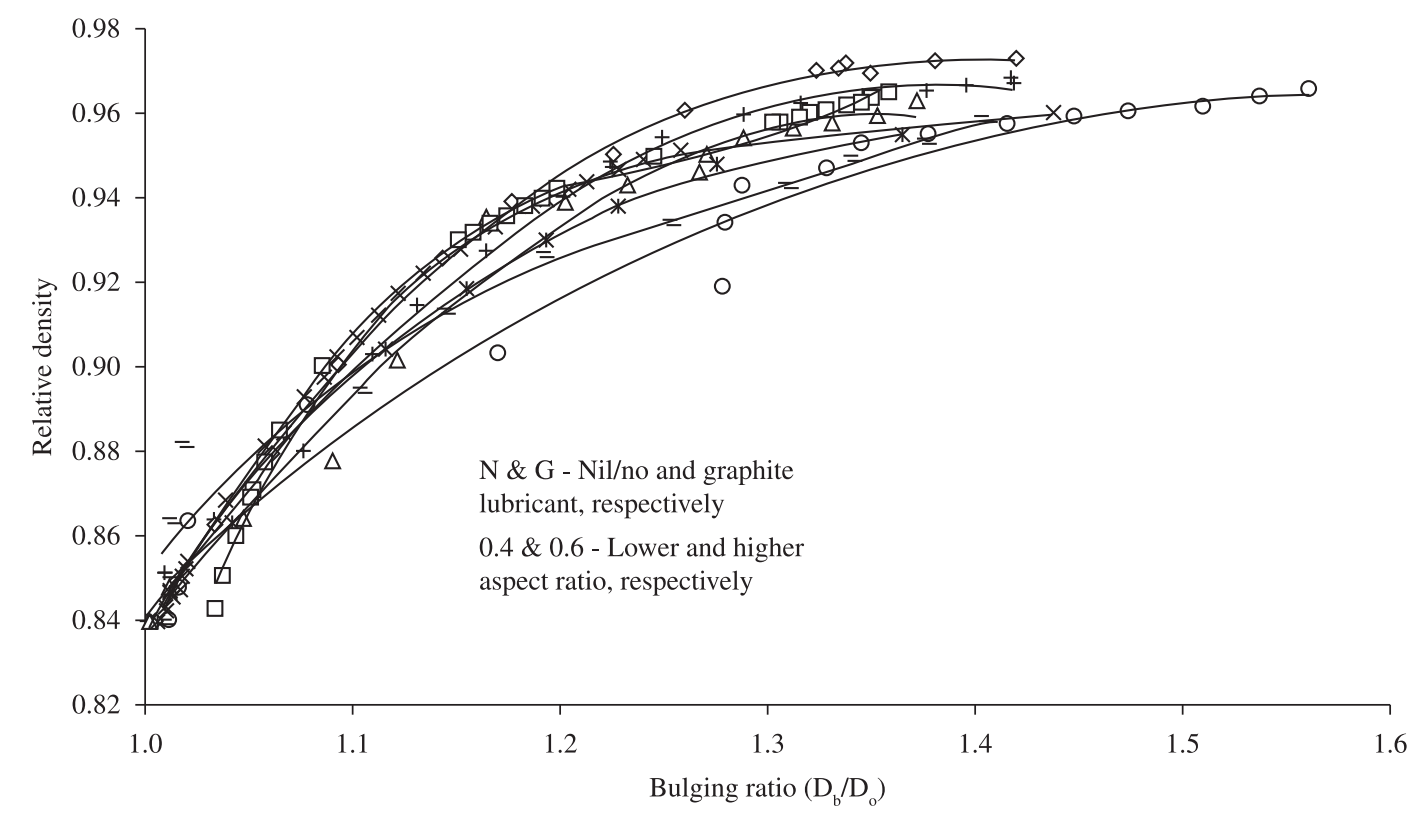

\footnotetext{
$\square \mathrm{Fe}-0.35 \% \mathrm{C},(\mathrm{N}),(0.6) \quad \times \mathrm{Fe}-0.35 \% \mathrm{C},(\mathrm{G}),(0.6) \quad \Delta \mathrm{Fe},(\mathrm{N}),(0.6) \quad \mathrm{Fe},(\mathrm{G}),(0.6) \diamond \mathrm{Fe}-0.75 \% \mathrm{C},(\mathrm{N}),(0.6)$ $* \mathrm{Fe}-0.75 \% \mathrm{C},(\mathrm{G}),(0.6)+\mathrm{Fe}-1.1 \% \mathrm{C},(\mathrm{N}),(0.6)-\mathrm{Fe}-1.1 \% \mathrm{C},(\mathrm{G}),(0.6)$
}

Figure 3. Variation of relative density against bulging ratio of plain carbon steel P/M preforms of aspect ratio of 0.6 during cold upsetting. 


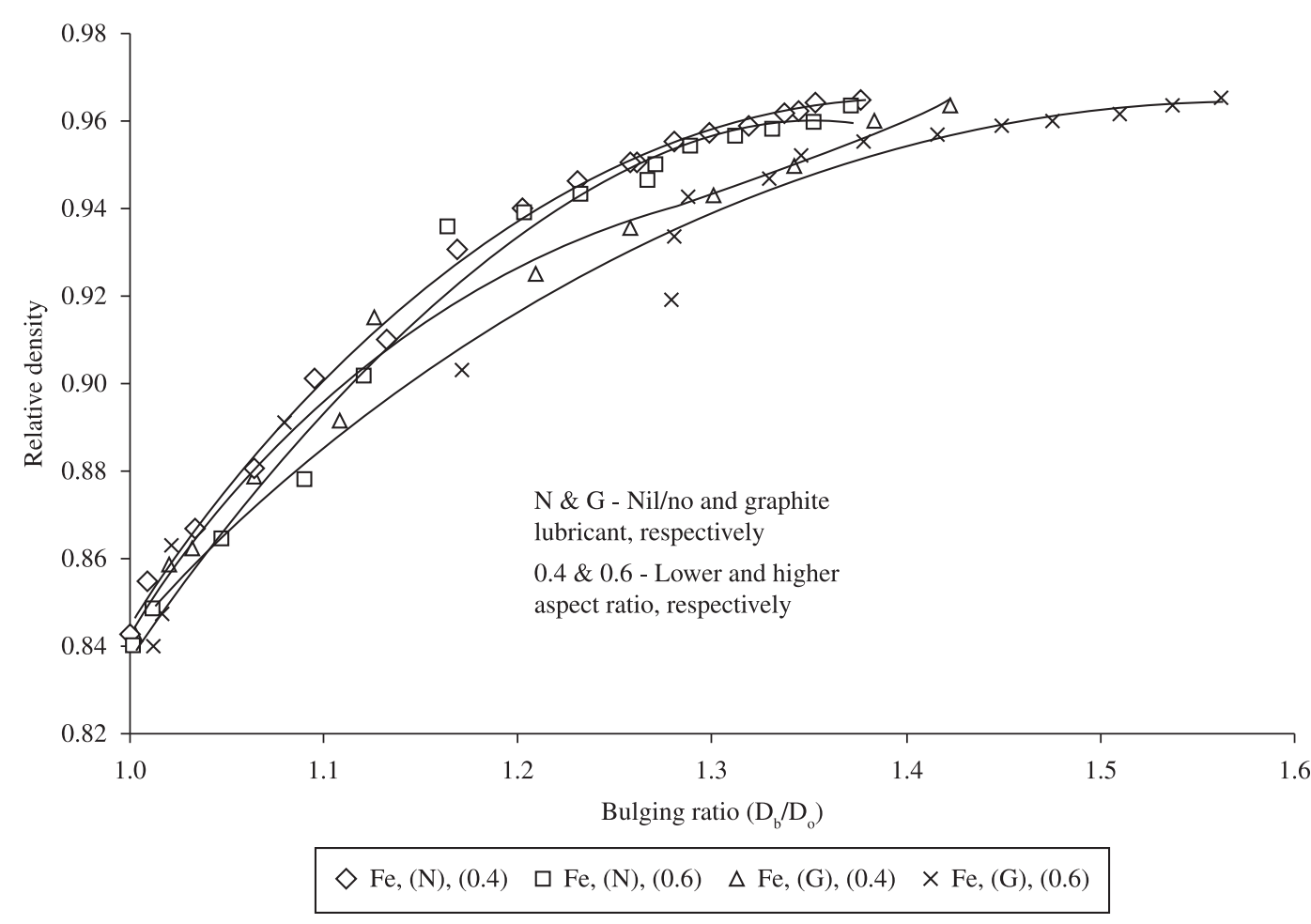

Figure 4. Variation of relative density against bulging ratio for pure iron P/M preforms.

that higher aspect ratio preform showed poor densification in comparison to lower aspect ratio preform. The nil/no lubricant condition (Figure 4) exhibits higher densification rate right from the start of deformation (84\% theoretical) to around $96 \%$ theoretical density when compared to the graphite lubricant condition. Thereafter, irrespective of the aspect ratio and lubricants employed, the final density achieved is almost equal.

Axial deformation of sintered P/M material undergoes a complex phenomenon as some material flows into the pores and hence, does not follow the volume constancy principle. Bulging due to frictional constraints increases the circumferential stresses and the presence of pores in the $\mathrm{P} / \mathrm{M}$ material causes the material to fail or fracture. Due to the lateral deformation and bulging of $\mathrm{P} / \mathrm{M}$ preform occurring simultaneously during the deformation process, the effect of bulging on the densification and forming behaviour of plain carbon steel preforms can be better studied by analyzing actual bulged length (Figure 1) given by $x=\left(D_{b}-D_{c}\right) / 2$. Figure 5 is plotted to show the relationship between actual bulged strain against relative density of plain carbon steel $\mathrm{P} / \mathrm{M}$ preforms of aspect ratio of 0.4 and 0.6 , respectively, cold upset under two different frictional, namely, nil/no and graphite lubricant condition. The actual bulged strain is determined by subtracting the contact diameter strain from the bulged diameter strain. It is evident that for any given actual bulged strain the relative density is higher in the case of graphite employed lubricant preforms. With lubrication between the preform and die contact surfaces the lateral deformation is pronounced in comparison to nil/no lubricant condition, hence, higher densification rate is achieved for graphite employed lubricant preform for lower levels of bulged strain. Also, at the final stages of deformation (4-5\% pores left in the preform) the pores were stabilized and the preform can be treated as a fully dense material, hence, bulging was highly pronounced. Further, higher densification rate is achieved for iron-carbon alloy preforms in comparison to pure iron preform. Apart from iron-to-iron bonding the carbon particles diffuse into the ferrous matrix during the sintering process. Another important factor affecting the properties of the sintered steel preform is the combination of carbon with iron particles. The pore size is affected by the above phenomenon together with shrinkage during the sintering process. As the amount of the smaller carbon particles $(2-3 \mu \mathrm{m})$ increases in the preform the pore size reduces and these are effectively closed. The larger size pores spread out in lateral direction more than the smaller pores, hence, the densification rate is reduced for the pure iron preforms at same level of actual bulged strain. Narayanasamy et al. ${ }^{21}$ had presented the microstructure of pure iron, $\mathrm{Fe}-0.4 \% \mathrm{C}$ and $\mathrm{Fe}-0.8 \% \mathrm{C}$ and it can be seen that as the smaller carbon particle size increases in the preform the pore size reduces. Further, they reported better densification for carbon steels compared to pure iron.

Figure 6 is plotted to show the relationship between hydrostatic stress against actual bulged strain for pure iron preform under the influence of preform geometry and lubricant conditions. The hydrostatic stress $\left(\sigma_{m}\right)$ is calculated using the following Equation 1 (here for axisymmetric forging, $\sigma_{r}=\sigma_{\theta}$ ); 


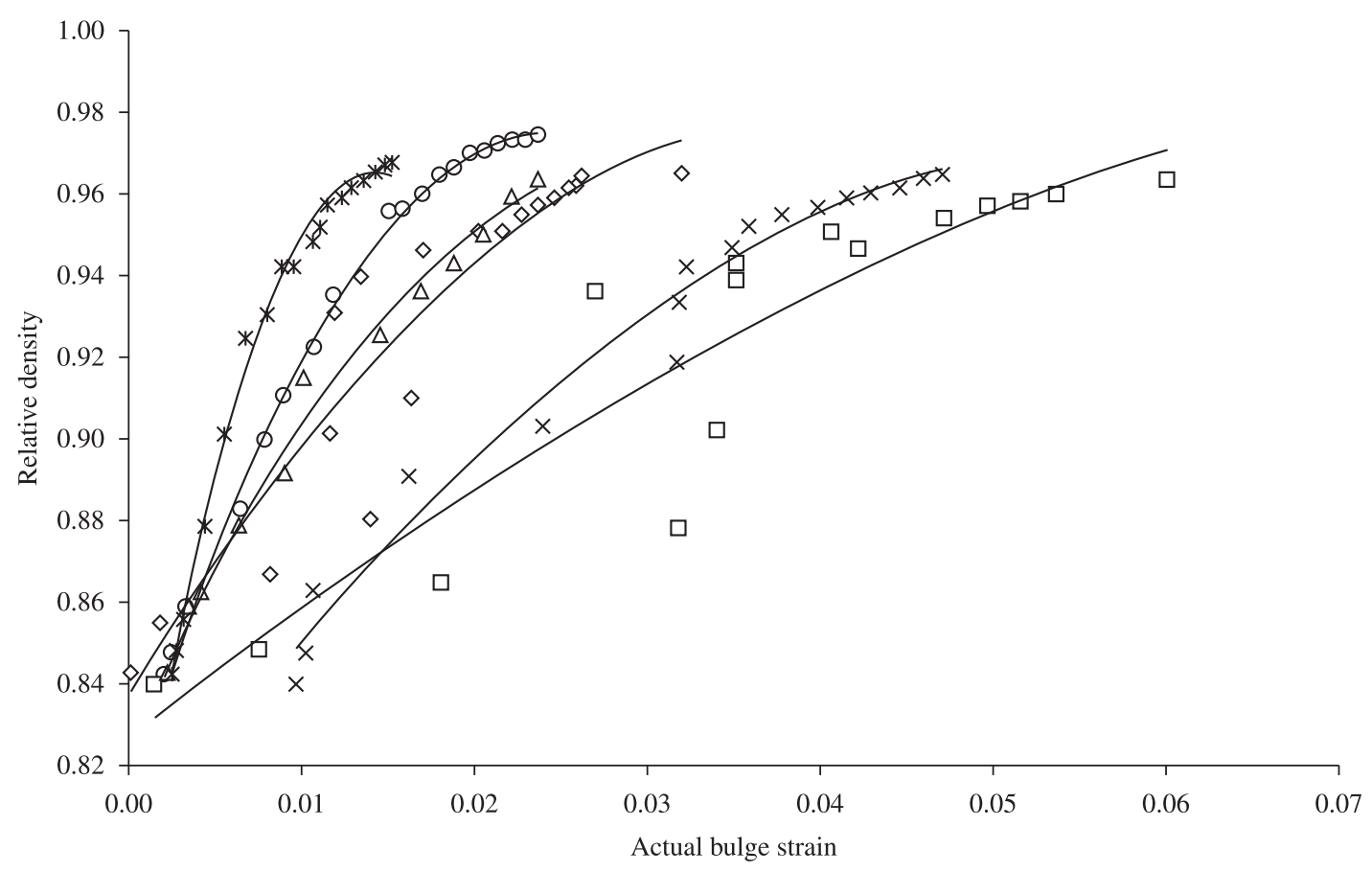

$\diamond \mathrm{Fe},(\mathrm{N}),(0.4) \quad \square \mathrm{Fe},(\mathrm{N}),(0.6) \quad \Delta \mathrm{Fe},(\mathrm{G}),(0.4) \quad \times \mathrm{Fe},(\mathrm{G}),(0.6)$

$* \mathrm{Fe}-0.75 \% \mathrm{C},(\mathrm{N}),(0.4) \quad \mathrm{Fe}-1.1 \% \mathrm{C},(\mathrm{N}),(0.4)$

Figure 5. Relative density against actual bulge strain for plain carbon steel P/M preforms during cold upsetting.

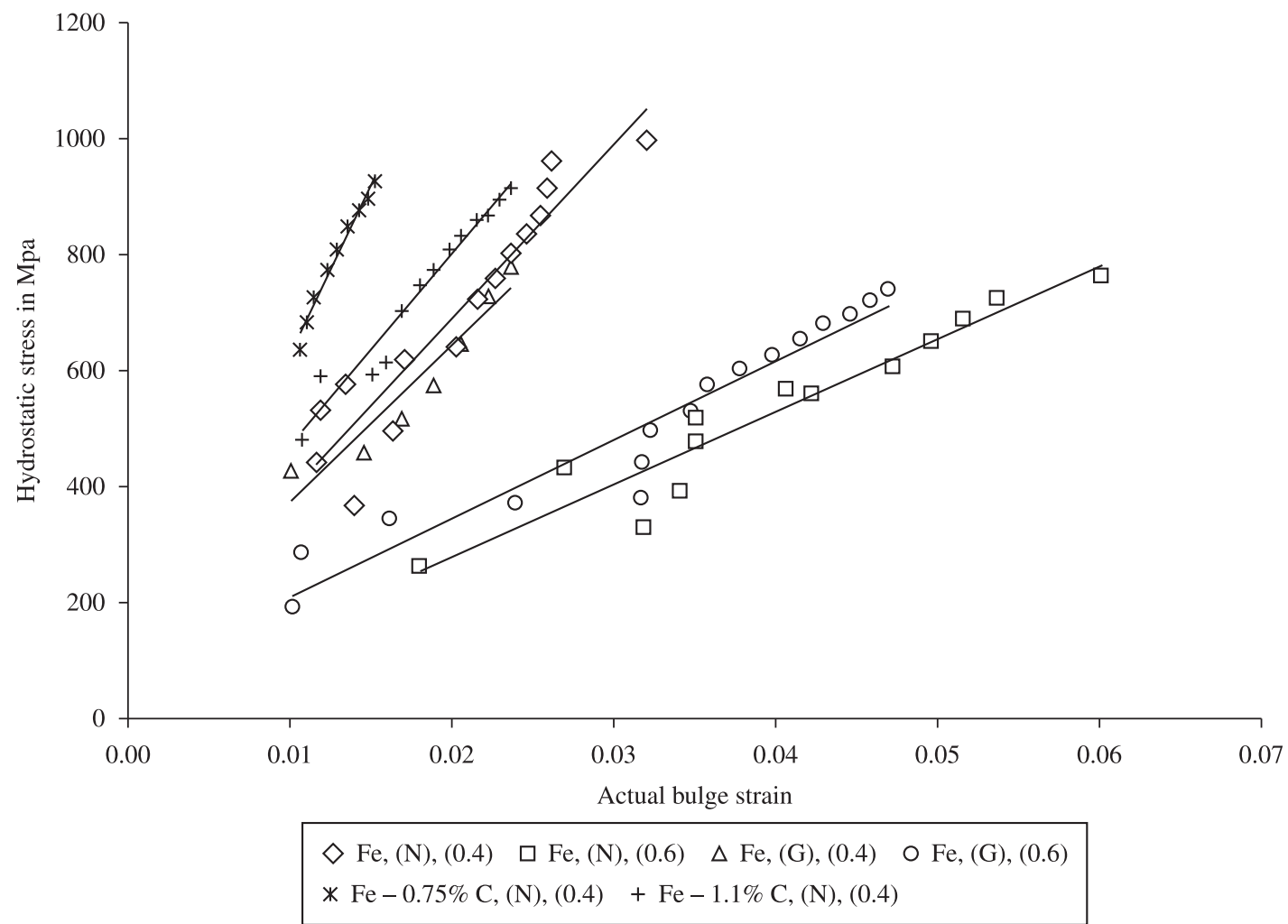

Figure 6. Hydrostatic stress against actual bulge strain for plain carbon steel P/M preforms of aspect ratio of 0.4 during cold upsetting. 


$$
\sigma_{m}=\frac{\sigma_{r}+\sigma_{\theta}+\sigma_{z}}{3}=\frac{2 \sigma_{\theta}+\sigma_{z}}{3}
$$

where $\sigma_{\theta}, \sigma_{r}$ and $\sigma_{z}$ are the hoop stress, radial stress and axial stress, respectively, and are calculated under triaxial stress state conditions by the following Equations 2 and 3;

$\sigma_{\theta}=\left[\frac{2 \alpha+R^{2}}{2-R^{2}+2 R^{2} \alpha}\right] \sigma_{z}$

where, $\alpha=\frac{d \varepsilon_{\theta}}{d \varepsilon_{z}}$, and

$\sigma_{z}=\frac{P}{A_{o}}$

The Equation 4 for axial strain for P/M materials is

$\varepsilon_{z}=\ln \left(\frac{h_{o}}{h_{f}}\right)$

and true hoop strain is (Equation 5)

$\varepsilon_{\theta}=\ln \left(\frac{2 D_{\mathrm{b}}^{2}+D_{\mathrm{c}}^{2}}{3 D_{\mathrm{o}}^{2}}\right)$

where, $P$ is the axial load; $A_{o}$ is the initial contact surface area; $\varepsilon_{z}$ is the true axial strain; $\varepsilon \theta$ is the true hoop strain; $h_{o}$ is the initial height of the preform; $h_{f}$ is the forged height of the preform; $D_{b}$ is the forged bulged diameter of the preform; $D_{c}$ is the forged contact diameter of the preform; $D_{o}$ is the initial diameter of the preform and $R$ is the relative density of the preform.
It can be seen that for any given actual bulged strain the hydrostatic stress is enhanced in the case of lower aspect ratio. Lower aspect ratio preforms have a lower pore bed height and the densification rate is higher (Figure 4) in comparison to higher aspect ratio preform. This is the reason for higher hydrostatic stress for lower levels of actual bulged strain in lower aspect ratio preforms. Further, the actual bulged strain to fracture is extended for the case of nil/ no lubricant condition. Due to the high induced friction at the die contact surface for nil/no lubrication condition and lower porosity in the preform in comparison to graphite lubricant condition, the lateral deformation contributes to high material flow at the middle of the preform rather than at the contact surface. This is the reason for higher bulge strain in nil/no lubricant preforms.

Figures 7 and 8 are plotted to evaluate the power law relationship between percent theoretical density and hydrostatic stress, respectively, with the bulging ratio. It can be clearly seen from Figure 7 that the bulging kinetics follow three different mechanisms, however, against hydrostatic stress it follows two different mechanisms (Figure 8). Each of these stages observed in Figures 7 and 8 can be expressed as a power law relation between percent theoretical density $\left(\% \frac{\rho_{f}}{\rho_{t h}}\right)$ and bulging ratio and hydrostatic stress $\left(\sigma_{m}\right)$ and bulging ratio, respectively, as follows (Equations 6 and 7):

$\% \frac{\rho_{f}}{\rho_{t h}}=B\left(\frac{D_{b}}{D_{o}}\right)^{m}$

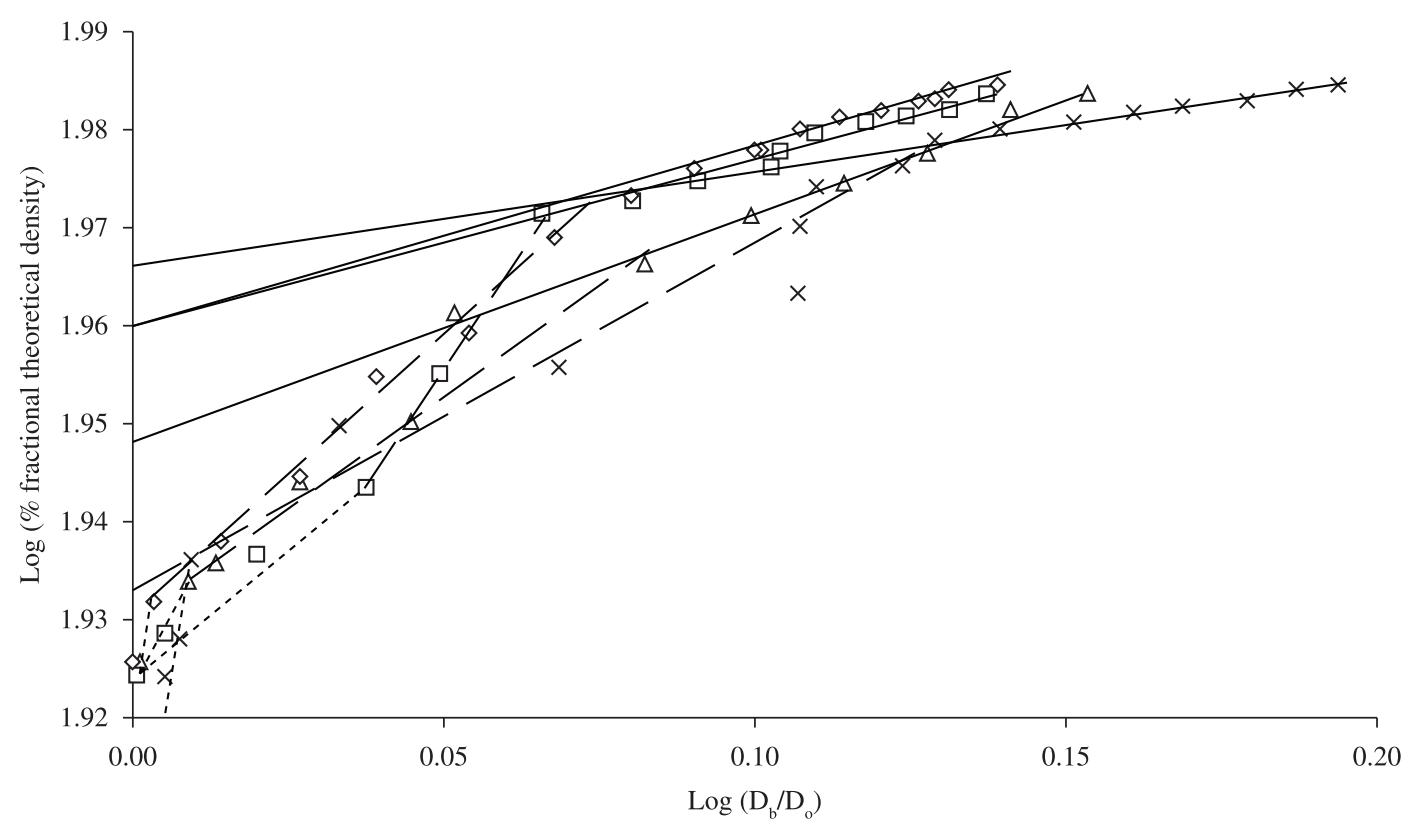

$\diamond \mathrm{Fe},(\mathrm{N}),(0.4) \quad \square \mathrm{Fe},(\mathrm{N}),(0.6) \quad \Delta \mathrm{Fe},(\mathrm{G}),(0.4) \quad \times \mathrm{Fe},(\mathrm{G}),(0.6)$

Figure 7. Influence of friction conditions and preform geometry on the behaviour of $\log (\%$ fractional theoretical density) as a function of $\log \left(\mathrm{D}_{\mathrm{b}} / \mathrm{D}_{\mathrm{o}}\right)$ for sintered Fe preforms during cold upsetting. 


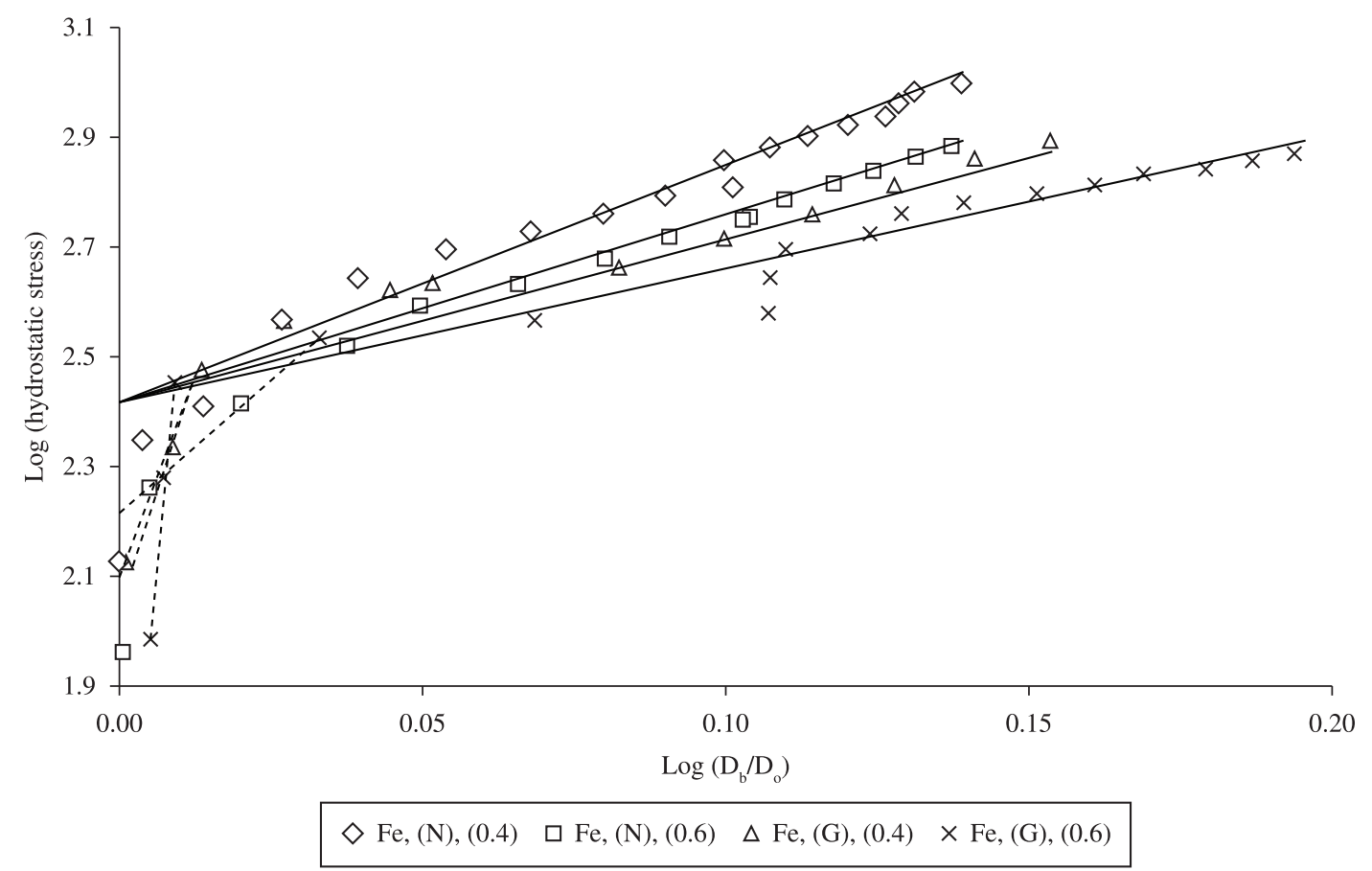

Figure 8. Influence of friction conditions and preform geometry on the behaviour of $\log$ (hydrostatic stress) as a function of $\log \left(\mathrm{D}_{\mathrm{b}} / \mathrm{D}_{\mathrm{o}}\right)$ for sintered Fe preforms during cold upsetting.

Table 3. Influence of preform geometry and lubricants on the constants of the power law equations (Equations 6 and 7) for pure iron preform during cold upsetting.

\begin{tabular}{|c|c|c|c|c|c|c|c|c|}
\hline \multirow{2}{*}{$\begin{array}{c}\text { Lubricant } \\
\text { used }\end{array}$} & \multirow{2}{*}{$\begin{array}{l}\text { Aspect } \\
\text { ratio }\end{array}$} & \multirow[t]{2}{*}{ Stage } & \multicolumn{2}{|c|}{ Constants } & \multirow{2}{*}{$\begin{array}{c}\text { Validity } \\
\text { range }\end{array}$} & \multicolumn{2}{|c|}{ Constants } & \multirow{2}{*}{$\begin{array}{c}\text { Validity } \\
\text { range }\end{array}$} \\
\hline & & & $B$ & $m$ & & $C$ & $n$ & \\
\hline \multirow{6}{*}{$\mathrm{Nil} / \mathrm{n}^{\circ}$} & \multirow{3}{*}{0.4} & 1 & 84.00 & 0.6573 & $84.00-85.48$ & 123.71 & 28.411 & $0-257$ \\
\hline & & 2 & 85.09 & 0.5750 & $85.48-94.00$ & 270.93 & 4.082 & $257-998$ \\
\hline & & 3 & 91.50 & 0.1730 & $94.00-96.50$ & - & - & - \\
\hline & \multirow{3}{*}{0.6} & 1 & 83.99 & 0.5163 & $84.00-87.76$ & 162.97 & 9.353 & $0-329$ \\
\hline & & 2 & 85.61 & 0.9824 & $87.76-93.58$ & 266.98 & 3.326 & $329-764$ \\
\hline & & 3 & 91.12 & 0.1747 & $93.58-96.30$ & - & - & - \\
\hline \multirow{6}{*}{ Graphite } & \multirow{3}{*}{0.4} & 1 & 84.00 & 1.1053 & $84.00-85.89$ & 123.71 & 28.411 & $0-301$ \\
\hline & & 2 & 85.14 & 0.4408 & $85.89-92.55$ & 253.05 & 3.187 & $301-780$ \\
\hline & & 3 & 88.34 & 0.2461 & $92.55-96.36$ & - & - & - \\
\hline & \multirow{3}{*}{0.6} & 1 & 83.95 & 2.786 & $84.00-86.29$ & 25.91 & 111.81 & $0-284$ \\
\hline & & 2 & 85.64 & 0.3579 & $86.29-95.24$ & 270.59 & 2.256 & $284-740$ \\
\hline & & 3 & 92.74 & 0.0900 & $95.24-96.51$ & - & - & - \\
\hline
\end{tabular}

$$
\sigma_{m}=C\left(\frac{D_{b}}{D_{o}}\right)^{n}
$$

where $B, m, C$ and $n$ are experimentally determined constants. Equation 6 has three different constants for ' $B$ ' and ' $m$ ' corresponding to each stage and similarly Equation 7 has two different constants for ' $C$ ' and ' $n$ ' corresponding to each stage, which are given in Table 3. It can be seen that the values of ' $B$ ' at the first stage is corresponding to the initial theoretical density irrespective of aspect ratio and lubricants employed. During the second stage and third stage the values of ' $B$ ' are again in very close proximity, respectively, for both aspect ratio and lubricants employed. The variations between the minimum and the maximum values for each stage are calculated to be 0.64 percent and 4.7 percent, respectively. Hence, it can be concluded that the ' $B$ ' value remains the same for each stage irrespective of aspect ratio and lubricant conditions. Further, the values of ' $B$ ' increases from stage 1 to stage 3 indicating enhancements in densification as deformation progresses. The values of ' $m$ ' decreases from stage 1 to stage 3 and contributes to decreases in densification, however, much less than that of 
the positive contribution of constant ' $B$ ', hence, the overall densification increases. Further, the effect of aspect ratio and lubricant condition on the values of ' $m$ ' is literally nil. Similar behaviour of constants ' $C$ ' and ' $n$ ' are observed as discussed for constants ' $B$ ' and ' $m$ '.

Tables 4-7 show the results at the final stage of cold upsetting of sintered pure iron preforms for different aspect ratio under different lubricants employed. A few values of bulging ratio and percent theoretical density during the final stage are chosen together with the power law coefficient derived in Table 3 for the last stage and are used to calculate the percent theoretical density and hydrostatic stress. These calculated values are compared to the measured values and percentage errors are presented in Tables 4-7. Further, to achieve the $100 \%$ density the required hydrostatic pressure and the calculated bulged diameter are presented in Tables 4-7. As seen in these tables the percentage error is less than $0.5 \%$. It can be concluded that the power law equations to calculate the hydrostatic stress and percent theoretical density are justified and is in good agreement with Rajeshkannan et al. ${ }^{9}$. Further, it can be seen that the calculated bulge diameter at $100 \%$ density increases with increasing aspect ratio and reducing frictional constraints. However, this is not true for the calculated hydrostatic stress at $100 \%$ density.

Table 4. Cold upsetting data for sintered iron powder preform (aspect ratio $=0.4$ ) deformed under nil/no lubricating condition.

\begin{tabular}{|c|c|c|c|c|c|c|c|c|c|}
\hline Si. $n^{0}$ & $\mathbf{D}_{\mathrm{b}} / \mathbf{D}_{\mathrm{o}}$ & $\begin{array}{l}\text { Calculated } \\
\qquad \% \frac{\rho_{f}}{\rho_{t h}}\end{array}$ & $\begin{array}{c}\text { Measured } \\
\% \frac{\rho_{f}}{\rho_{t h}}\end{array}$ & $\%$ error & $\begin{array}{l}\text { Calculated } \sigma_{m} \\
(\mathrm{MPa})\end{array}$ & $\begin{array}{c}\text { Measured } \sigma_{m} \\
(\mathrm{MPa})\end{array}$ & $\%$ error & $\begin{array}{c}\text { Calculated } \\
\mathrm{D}_{\mathrm{b}} \text { at } 100 \% \\
\text { density }\end{array}$ & $\begin{array}{c}\text { Calculated } \\
\sigma_{m} \text { at } 100 \% \\
\text { density }\end{array}$ \\
\hline 1 & 1.3187 & 95.99 & 95.91 & 0.08 & 838.09 & 835.07 & 0.36 & & \\
\hline 2 & 1.3374 & 96.22 & 96.16 & 0.06 & 887.68 & 889.65 & 0.22 & & \\
\hline 3 & 1.3450 & 96.31 & 96.21 & 0.11 & 908.45 & 905.71 & 0.30 & $43.06 \mathrm{~mm}$ & $2204 \mathrm{MPa}$ \\
\hline 4 & 1.3524 & 96.41 & 96.41 & 0 & 929.03 & 930.82 & 0.19 & & \\
\hline 5 & 1.3764 & 96.70 & 96.49 & 0.22 & 998.19 & 997.70 & 0.05 & & \\
\hline
\end{tabular}

Table 5. Cold upsetting data for sintered iron powder preform (aspect ratio $=0.6$ ) deformed under nil/no lubricating condition.

\begin{tabular}{|c|c|c|c|c|c|c|c|c|c|}
\hline Si. $n^{0}$ & $\mathbf{D}_{\mathbf{b}} / \mathbf{D}_{\mathbf{o}}$ & $\begin{array}{c}\text { Calculated } \\
\qquad \frac{\rho_{f}}{\rho_{t h}}\end{array}$ & $\underset{\% \frac{\rho_{f}}{\rho_{t h}}}{\text { Measured }}$ & $\%$ error & $\begin{array}{l}\text { Calculated } \sigma_{m} \\
(\mathrm{MPa})\end{array}$ & $\begin{array}{c}\text { Measured } \sigma_{m} \\
(\mathrm{MPa})\end{array}$ & $\%$ error & $\begin{array}{c}\text { Calculated } \\
\mathrm{D}_{\mathrm{b}} \text { at } 100 \% \\
\text { density }\end{array}$ & $\begin{array}{c}\text { Calculated } \\
\sigma_{m} \text { at } 100 \% \\
\text { density }\end{array}$ \\
\hline 1 & 1.2882 & 95.24 & 95.41 & 0.18 & 619.85 & 617.55 & 0.37 & & \\
\hline 2 & 1.3120 & 95.55 & 95.65 & 0.11 & 658.76 & 657.42 & 0.20 & & \\
\hline 3 & 1.3320 & 95.80 & 95.78 & 0.02 & 692.76 & 690.95 & 0.26 & $44.43 \mathrm{~mm}$ & $1569 \mathrm{MPa}$ \\
\hline 4 & 1.3534 & 96.07 & 95.95 & 0.12 & 730.47 & 730.84 & 0.05 & & \\
\hline 5 & 1.3718 & 96.29 & 96.30 & 0.01 & 764.03 & 764.11 & 0.01 & & \\
\hline
\end{tabular}

Table 6. Cold upsetting data for sintered iron powder preform (aspect ratio $=0.4$ ) deformed under graphite lubricating condition.

\begin{tabular}{|c|c|c|c|c|c|c|c|c|c|}
\hline Si. $n^{o}$ & $D_{b} / D_{o}$ & $\begin{array}{l}\text { Calculated } \\
\qquad \frac{\rho_{f}}{\rho_{t h}}\end{array}$ & $\begin{array}{c}\text { Measured } \\
\% \frac{\rho_{f}}{\rho_{t h}}\end{array}$ & $\%$ error & $\begin{array}{l}\text { Calculated } \sigma_{m} \\
\quad(\mathrm{MPa})\end{array}$ & $\begin{array}{c}\text { Measured } \sigma_{m} \\
(\mathrm{MPa})\end{array}$ & $\%$ error & $\begin{array}{c}\text { Calculated } \\
\mathrm{D}_{\mathrm{b}} \text { at } 100 \% \\
\text { density }\end{array}$ & $\begin{array}{c}\text { Calculated } \\
\sigma_{m} \text { at } 100 \% \\
\text { density }\end{array}$ \\
\hline 1 & 1.2574 & 93.46 & 93.60 & 0.15 & 525.08 & 525.86 & 0.15 & & \\
\hline 2 & 1.3010 & 94.25 & 94.34 & 0.10 & 585.34 & 583.24 & 0.36 & & \\
\hline 3 & 1.3421 & 94.97 & 95.01 & 0.04 & 646.33 & 647.12 & 0.12 & $43.14 \mathrm{~mm}$ & $1261 \mathrm{MPa}$ \\
\hline 4 & 1.3836 & 95.69 & 95.98 & 0.30 & 712.21 & 710.24 & 0.28 & & \\
\hline 5 & 1.4235 & 96.36 & 96.36 & 0 & 779.75 & 780.36 & 0.08 & & \\
\hline
\end{tabular}

Table 7. Cold upsetting data for sintered iron powder preform (aspect ratio $=0.6$ ) deformed under graphite lubricating condition.

\begin{tabular}{|c|c|c|c|c|c|c|c|c|c|}
\hline Si. $n^{0}$ & $\mathbf{D}_{\mathrm{b}} / \mathbf{D}_{\mathrm{o}}$ & $\begin{array}{c}\text { Calculated } \\
\qquad \frac{\rho_{f}}{\rho_{t h}}\end{array}$ & $\begin{array}{c}\text { Measured } \\
\% \frac{\rho_{f}}{\rho_{t h}}\end{array}$ & $\%$ error & $\begin{array}{l}\text { Calculated } \sigma_{m} \\
(\mathrm{MPa})\end{array}$ & $\begin{array}{c}\text { Measured } \sigma_{m} \\
(\mathrm{MPa})\end{array}$ & $\%$ error & $\begin{array}{c}\text { Calculated } \\
\mathrm{D}_{\mathrm{b}} \text { at } 100 \% \\
\text { density }\end{array}$ & $\begin{array}{c}\text { Calculated } \\
\sigma_{m} \text { at } 100 \% \\
\text { density }\end{array}$ \\
\hline 1 & 1.4487 & 95.89 & 95.89 & 0 & 624.42 & 622.95 & 0.24 & & \\
\hline 2 & 1.4748 & 96.04 & 96.01 & 0.03 & 650.09 & 648.25 & 0.28 & & \\
\hline 3 & 1.5100 & 96.24 & 96.14 & 0.11 & 685.62 & 685.55 & 0.01 & $58.71 \mathrm{~mm}$ & $1790 \mathrm{MPa}$ \\
\hline 4 & 1.5374 & 96.40 & 96.38 & 0.02 & 714.01 & 716.58 & 0.36 & & \\
\hline 5 & 1.5622 & 96.54 & 96.51 & 0.03 & 740.26 & 740.05 & 0.03 & & \\
\hline
\end{tabular}




\section{Conclusions}

The major conclusions have been drawn from the present investigations are as follows

- Irrespective of preform geometry and frictional constraints during deformation the curves of relative density against $D_{b} / D_{o}$ and hydrostatic stress against $D_{b} / D_{o}$ follow the power law relation of the form $\% \frac{\rho_{f}}{\rho_{t h}}=B\left(\frac{D_{b}}{D_{o}}\right)^{m}$ and $\sigma_{m}=C\left(\frac{D_{b}}{D_{o}}\right)^{n}$ respectively;

\section{References}

1. Liu Y, Chen LF, Tang HP, Liu CT, Liu B and Huang BY. Design of powder metallurgy titanium alloys and composites. Material Science Engineering A. 2006; 418:25-35. http:// dx.doi.org/10.1016/j.msea.2005.10.057

2. Hua L, Qin X, Mao H and Zhao Y. Plastic deformation and yield criterion for compressible sintered powder materials. Journal of Materials Processing Technology. 2006; 180:174-178. http:// dx.doi.org/10.1016/j.jmatprotec.2006.06.001

3. Rajeshkannan A and Narayan S. Strain hardening behaviour in sintered $\mathrm{Fe}-0.8 \% \mathrm{C}-1.0 \% \mathrm{Si}-0.8 \% \mathrm{Cu}$ powder metallurgy preform during cold upsetting. Journal of Engineering Manufacture. 2009; 223:1567-1574. http://dx.doi. org/10.1243/09544054JEM1587

4. Selvakumar N, Ganesan P, Radha P, Narayanasamy R and Pandey KS. Modelling the effect of particle size and iron content on forming of Al-Fe composite preforms using neural network. Material Design. 2007; 28:119-130. http://dx.doi. org/10.1016/j.matdes.2005.05.004

5. Zhang XQ, Peng YH, Li MQ, Wu SC and Ruan XY. Study of workability limits of porous materials under different upsetting conditions by compressible rigid plastic finite element method. Journal of Materials Engineering and Performance. 2000; 9:164-169. http://dx.doi. org/10.1361/105994900770346114

6. Narayanasamy R and Selvakumar N. Deformation behaviour of cold upset forming of sintered Al-Fe composite preforms. Journal of Engineering Materials and Technology. 2005; 127:251-256. http://dx.doi.org/10.1115/1.1867984

7. Rajeshkannan A, Pandey KS, Shanmugam S and Narayanasamy R. Sintered Fe- $0.8 \% \mathrm{C}-1.0 \% \mathrm{Si}-0.4 \% \mathrm{Cu}$ P/M preform behaviour during cold upsetting. Journal of Iron and Steel Research International. 2008; 15:81-87. http://dx.doi.org/10.1016/ S1006-706X(08)60254-X

8. Narayanasamy R and Pandey KS. A study on the barreling of sintered iron preforms during hot upset forging. Journal of Materials Processing Technology. 2000; 100:87-94. http:// dx.doi.org/10.1016/S0924-0136(99)00457-4

9. Rajeshkannan A, Pandey KS and Shanmugam S. Some studies on barreling of powder preforms during cold upsetting. Journal of Mechanical Behaviour of Materials. 2006; 17:415-430.

10. Baskaran K and Narayanasamy R. Some aspects of barreling in elliptical shaped billets of aluminium during cold upset forging with lubricant. Materials Design. 2008; 29:638-661. http://dx.doi.org/10.1016/j.matdes.2006.04.018

11. Cetinarslan CS. Effect of aspect ratio on barreling contour and variation of total surface area during upsetting of cylindrical
- Densification rate was enhanced for lower aspect ratio preforms deformed under increased frictional constrains when plotted against bulging ratio, however, against actual bulged strain graphite employed preforms showed higher levels of densification;

- Densification and hydrostatic stress were found to be higher in the case of iron-carbon alloy and lower aspect ratio preforms.

specimen. Materials and Design. 2007; 28:1907-1913. http:// dx.doi.org/10.1016/j.matdes.2006.03.027

12. Thaheer ASA and Narayanasamy R. Comparison of barreling in lubricated truncated cone billets during cold upset forging of various metals. Materials and Design. 2008; 29:1027-1035. http://dx.doi.org/10.1016/j.matdes.2006.05.026

13. Narayanasamy R, Sathiyanarayanan S and Ponalagusamy R. A study on barreling in magnesium alloy solid cylinders during cold upset forming. Journal of Materials Processing Technology. 2000; 101:64-69. http://dx.doi.org/10.1016/ S0924-0136(99)00473-2

14. Rajeshkannan A, Pandey KS and Shanmugam S. Some investigation on the cold deformation behaviour of sintered iron- $0.8 \%$ carbon alloy powder preforms. Journal of Materials Processing Technology. 2008; 203:542-547. http://dx.doi. org/10.1016/j.jmatprotec.2007.10.068

15. Rahman MA and El-Sheikh MN. Workability in forging of powder metallurgy compacts. Journal of Materials Processing Technology. 1995; 54:97-102. http://dx.doi.org/10.1016/09240136(95)01926-X

16. Simchi A. Effects of lubrication procedure on the consolidation, sintering and microstructural features of powder compacts. Materials Design. 2003; 24:585-594. http://dx.doi.org/10.1016/ S0261-3069(03)00155-9

17. Li XL, Peng DS, Liu JA and Liu ZQ. An experiment study of the lubrication behaviour of graphite in hot compression tests of Ti-6Al-4V alloy. Journal of Materials Processing Technology. 2001; 112:1-5. http://dx.doi.org/10.1016/S09240136(00)00845-1

18. Lee SR, Lee YK, Park CH and Yang DY. A new method of preform design in hot forging by using electric field theory. International Journal of Mechanical Sciences. 2002; 44:773792. http://dx.doi.org/10.1016/S0020-7403(02)00003-6

19. Butuc MC, Gracio JJ and Rocha BA. An experimental and theoretical analysis on the application of stress-based forming limit criterion. International Journal of Mechanical Sciences. 2006; 48:414-429. http://dx.doi.org/10.1016/j. ijmecsci.2005.11.007

20. Rajeshkannan A and Pandey KS, Shanmugam S, Narayanasamy R, Narayan S. Some studies on sintered cold deformed plain carbon alloy steels. Materials and Design. 2012; 33:115-120. http://dx.doi.org/10.1016/j.matdes.2011.07.020

21. Narayanasamy R, Anandakrishnan V and Pandey KS. Effect of carbon content on workability of powder metallurgy steels. Material Science Engineering A. 2008; 494:337-342. http:// dx.doi.org/10.1016/j.msea.2008.04.022 